\title{
A cross sectional study to assess the prevalence of malocclusion in 08-12 years old school age children of the selected urban \& rural community of Bangladesh
}

Faria Tabassum Tanni ${ }^{1 *}$, Tanzila Rafique ${ }^{2}$,Tanjila Akter ${ }^{3}$, Khanum Huzzatun Nahar Khawla Binta Harun ${ }^{4}$,Gazi Shamim Hasssan ${ }^{5}$

AFFILIATION:

1.Faria Tabassum Tanni

BDS (Dhaka Dental College), MS (Orthodontics)

Bangabandhu Sheikh Mujib Medical University,Dhaka,Bangladesh.

E-mail: fariatabu@yahoo.com

https://orcid.org/0000-0001-9518-2035

2.Tanzila Rafique

Assistant professor, Department of orthodontics,

Faculty of dentistry,

Bangabandhu Sheikh Mujib Medical University,Dhaka,Bangladesh.

E-mail: tanzila rafique@bsmmu.edu.bd

3.Tanjila Akter

BDS (Dhaka Dental College), MS (Orthodontics)

Bangabandhu Sheikh Mujib Medical University, Dhaka,

Bangladesh.

E-mail: tamannatanjil@gmail.com

4.Khanum Huzzatun Nahar Khawla Binta Harun

Lecturer, Department of Orthodontics

Dhaka Dental College and Hospital, Dhaka, Bangladesh.

E-mail: dr.khawla80@gmail.com

5.Gazi Shamim Hasssan

Professor, Department of Orthodontics,

Faculty of dentistry, Bangabandhu Sheikh Mujib Medical

University, Dhaka, Bangladesh.

E-mai:drgazishamim@yahoo.com

Article info.

Received: 29 May 2021

Accepted: 26 July 2021

Volume: Vol-11, Issue-2, October 2021

DOI: https://doi.org/10.3329/updcj.v11i2.56071

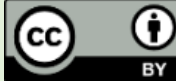

(C) Authors retain copyright and grant the journal right of first publication with the work simultaneously licensed under Creative Commons Attribution License CC - BY 4.0 that allows others to share the work with an acknowledgment of the work's authorship and initial publication in this journal.

https://creativecommons.org/licenses/by/4.0/

Publisher: Update Dental College, Dhaka, Bangladesh

Web: www.updatedentalcollege.edu.bd

E-mail: updcj@hotmail.com

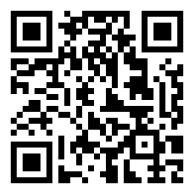

Scan QR code to see the latest issue

* Corresponding Author

Faria Tabassum Tanni

Department of orthodontics, Faculty of dentistry,

Bangabandhu Sheikh Mujib Medical University, Dhaka, Bangladesh.

E-mail: fariatabu@yahoo.com

https://orcid.org/0000-0001-9518-2035

Cell: +8801771166359
ABSTRACT:

Objective: To determine the prevalence of malocclusion in school-age children from a selective area of the urban and rural community of Bangladesh.

Methods: A cross-sectional descriptive survey was conducted among 748 children aged $08-12$ years old were examined from October 2019 to September 2020 in Sylhet Sardar Upazila, Bangladesh. Angle"s classification was used for recording molar relationship with malocclusion traits. The study participants were examined by disposable dental tools (calibrated probs and mirror) including torchlight. After the collection of all data, it was compiled and analyzed by Statistical Package for the Social Sciences (SPSS) Windows version 23. Chi-square test was used for categorical variables. $P$ values $<0.05$ was considered as statistically significant.

Result: The prevalence of malocclusion in urban school-age children was 237(63.4\%) and in rural 213(57.0\%).In urban area, the prevalence of malocclusion was $109(58.3 \%)$ in boys and $128(68.4 \%)$ in girls group. The majority $(70.5 \%)$ were found Angle's class I in urban group and $148(69.5 \%)$ in rural. One forty three $(60.3 \%)$ patients were found increased overbite with malocclusion in urban group and $124(58.2 \%)$ in rural. Angle's class-I malocclusion and Increased overbite were the most commonly occurring malocclusion.

Conclusion: Prevalence of malocclusion was more in urban school age children when compared with rural. Malocclusion was significantly more in girls than boys in both urban and rural area. Angle's class-I malocclusion and Increased overbite were the most commonly occurring malocclusion of school age children from a selected urban and rural community of Bangladesh.

KEYWORDS: rural, urban, angle's classification, malocclusion, overbite.

\section{INTRODUCTION}

Malocclusion as a word means bad bite ${ }^{1}$. Malocclusion can be defined as an occlusion in which there is a mal-relationship between the arches in any of the planes or where there are anomalies in tooth position, number, form, and developmental position of teeth beyond normal limits ${ }^{2}$. The term malocclusion is a derivative of occlusion which is the contact relationship between upper and lower teeth when the mouth is fully closed as well as the relationship of the teeth within the same jaw. It may be primary which arise in the developing dentition or secondary, which arise in the adult as a result of tooth loss and consequent adjacent tooth movement ${ }^{3}$. The factors responsible for malocclusion include genetic and environmental factors, or a combination of both along with various local factors such as adverse or deleterious 
oral habits ${ }^{4}$. Malocclusion ranks second among the common dental diseases in children and young adults, next to dental caries ${ }^{5}$.Malocclusion is not a disease, but a developmental condition representing biological diversity. It is basically the clinically significant variations from normal morphology and range of growth. Malocclusion may be the result of a combination of minor variations from the normal and these combinations add on to produce a clinical problem ${ }^{6}$.Malocclusion can cause psychosocial problems related to impaired dentofacial esthetics ${ }^{7}$. It may also lead to problems of oral cavity (traumatic bite and cheek bite), and it may also be one of the factors of social embarrassment. The uptake of orthodontic treatment is influenced by the desire to look attractive, self-esteem, and self-perception of dental appearance ${ }^{8}$.

An Indian study reported the prevalence of malocclusion to be higher in urban (20.8\%) than rural (14.8\%) and more prevalent in Girls school children (21.8\%) than Boys $(13.2 \%)^{9}$. Another study in district Peshawar reported the difference in prevalence of malocclusion in rural and urban areas.The distinction in predominance of malocclusion in rural and urban younger students (60\% versus $55 \%$ ) was non-significant. In rural region, the predominance of malocclusion was $50.67 \%$ in Boys and $72.73 \%$ in Girls, while in urban it was $44.20 \%$ in Boys and $67.21 \%$ in Girls. The distinction in the commonness of malocclusion in boys and girls of two regions (rural and urban) was profoundly huge significant.The most common traits of malocclusion were Angle's class I and overcrowding. The least malocclusion was Angle's class III (3.85\% \& 6.29\%) ${ }^{10}$.

A cross sectional study was carried out to explore the prevalence of malocclusion among the age group of 15-25 years in Bangladeshi population. Among the respondent $82.6 \%$ have class I molar relation, $12.06 \%$ class II and $5.34 \%$ class III molar relation ${ }^{11}$. In another Bangladeshi study revealed that among the study population females were $57.1 \%$ and the males were $42.1 \%$.Among them, $6.7 \%$ belonged to 6 to 11 years, $20.5 \%$ belonged to 12 to 17 years and the remaining $72.8 \%$ were of $18-35$ years of age. Angles Class I malocclusion was seen to be the most prevalent (64.2\%). In incisor classification, Class I malocclusion was seen to be the most prevalent (38.3\%). Increase in overjet, deep overbite, crossbite, crowding and spacing were found in $35.34 \%, 40.3 \%$, $24.3 \%, 58.2 \%$ and $38.5 \%$ of the patients respectively in the department of Orthodontics and Dentofacial Orthopedics in Sapporo Dental College and Hospital from January 2013 to February $2018^{12}$.

Developing nations like Bangladesh face numerous difficulties in rendering oral human services as most of the populace lives in rural regions where oral health projects and preventive measures are a long way from fulfilling needs. Bangladesh being a developing country, there are still remote villages unaware of the advances in various fields; one such being

11| $P$ a g e orthodontics. The objective of this study to asses prevalence of malocclusion in rural and urban school children of selected community of Bangladesh.Planning and implementation of future school based awareness program can be carried out and their population can be benefitted by this study. So that preventive and early orthodontic treatment can be given earlier to school age children.

\section{METHODOLOGY}

A total of 748 school going children from two different area urban ( city) and rural (village) area of Sylhet Sadar Upazila in Sylhet district under Sylhet division of Bangladesh which consists of 374 children in each area from October 2019 to September 2020 were selected in this cross sectional study. The study was conducted under the guidance in the Department of Orthodontics, Faculty of Dentistry, Bangabandhu Sheikh Mujib Medical University (BSMMU), Dhaka.The inclusion criteria were 1) School- age children 08to 12 year old in selected school irrespective of sex without the history of previous orthodontic treatment. 2) Participants with completely erupted first permanent molars. The exclusion criteria were 1) Unwillingness of participants as well as their legal guardians in the study. 2) Mentally compromised participants and participants with craniofacial anomalies. Four primary school (Girls and Boys) were randomly selected from a total 115 primary schools (Girls/Boys) of sylhet Sadar Upazilla. Out of four schools, two were urban and two was in rural areas. The study subjects were selected from a list of 08to 12-year old children by using stratified random sampling procedures in each school. Boys and Girls were equally distributed.The participants were selected by criterion random sampling method which fulfills the predetermined selective criteria. A prior notification and written consent form were sent to the head of the school for permission to carry out the study. A written assent form was given to the participant prior to the commencement of the study. A written consent form was given to the participant's legal guardian. Materials and instruments required: 1) Informed written assent and consent forms from study participants along with their legal guardians,2) Preformed Data collection sheet 3) Pens 4) Torch light 5) Disposable diagnostic materials (calibrated probe, mirror) 6) Mask and 7) Gloves.

The study sample along with their guardians was requested to give their agreement to participate in the study. The teacher was given a brief introduction about the investigator to the children. The investigators were addressing any concerns or clarification that the students may require before carrying out the data collection. Their data was collected by the dental health checkup.The oral health education lecture was given to all the children in the school to create awareness about dental health and Orthodontic treatment. After taking informed

Website: https://www.banglajol.info/index.php/UpDCJ 
written consent from the guardians of study participants, assent from the minors and approval from the ethical committee of BSMMU, school children were examined in ordinary chair using torch light and disposable diagnostic tools (periodontal probe, mirror, measurement scale). Study models and radiograph was not taken. Class I,Class II and class III molar relationship and various traits of malocclusion was recorded by using Angle's classification. Over jet was measured by periodontal pocket measuring calibrated probe. It was increased when the horizontal space between upper and lower incisors are more than $3 \mathrm{~mm}$ or normal. The normal value of overbite is 1 to $3 \mathrm{~mm}$ but it varies with the length of incisors. When space remain between upper and lower teeth in centric occlusion then open bite was noted. Crossbite was recorded when there are an abnormal labiolingual or buccolingual relationship of the upper and lower teeth when the mouth was closed in normal occlusal position. Crowding was noted when there was overlying of two or more teeth or minimum $2 \mathrm{~mm}$ space lack in each quadrant. Spacing was collected when diastema was present between two nearby teeth or extra space of at least $2 \mathrm{~mm}$ was existing in each quadrant.

\section{ETHICAL CONSIDERATIONS:}

Prior to the commencement of this study, ethical approval by the Institutional Review Board (IRB) of BSMMU was taken. The study was maintaining all the ethical principles in all procedures according to the declaration of Helsinki. The aim and objectives of the study along with its procedure, risks and benefits was explained to the participants an essay understandable local language. Data was collected maintaining confidentiality and privacy of the participants strictly. It was assured that all information and records was kept confidentially and the procedure was helpful for both the clinician and the participants in making rational approach of the case management. All participants were having a case number to maintain their confidentiality; all date was represented by their case number, not by their name or any other personal information that may leak their confidentiality. A written and signed informed consent was obtained from all participants. The written informed consent was containing the study name, type of study, risk and benefit of the participants, confidentiality and their right to withdraw from the research. The informed consent was taken from the participants with their legal guardians who also was sign on the consent form. This study was not involve any drugs, placebo, records (hospital, medical, birth, death or other), organs, tissues, body fluids, the fetus, or the aborts. The participants were not getting any financial benefit.

\section{STATISTICAL ANALYSIS}

A database was prepared and statistical analyses were carried out by using the Statistical Package for Social Sciences (SPSS Statistics for Windows, Version 23.0. Armonk, NY: IBM

12| P a g e
Corp. 2015). Continuous data were expressed as mean \pm standard deviation (SD) and categorical data were expressed as frequency and percentages. Mean and standard deviation was computed for quantitative variables and was analyzed by unpaired " $\mathrm{t}$ " test. Chi square test was used for categorical variables. $P$ values $<0.05$ were considered statistically significant.

\section{RESULTS}

Figure 1 shows that almost two third (63.4\%) participants were found malocclusion in urban group and $213(57.0 \%$ ) in rural group. The difference was not statistically significant $(p>0.05)$ between two groups. Figure 2 shows that majority (70.5\%) participants were found Angle's class I in urban group and $148(69.5 \%)$ in rural group. The difference was not statistically significant $(p>0.05)$ between two groups. In urban area, 109(58.3\%) participants were found malocclusion in Boys and $128(68.4 \%)$ in Girls group. The difference was statistically significant $(p<0.05)$ between two groups (Table- 1$)$. In rural area, $96(51.3 \%)$ participants were found malocclusion in Boys and $117(62.6 \%)$ in Girls group. The difference was statistically significant $(p<0.05)$ between two groups (Table-2). Regarding malocclusion in urban and rural school age children $70(29.5 \%)$ participants were found increased overjet of malocclusion in urban group and $43(20.2 \%)$ in rural group. The difference was statistically significant $(p<0.05)$ between two groups. $143(60.3 \%)$ participants were found increased overbite of malocclusion in urban group and $124(58.2 \%)$ in rural group. $12(5.1 \%)$ participants were found open bite of malocclusion in urban group and $13(6.1 \%)$ in rural group. $21(8.9 \%)$ participants were found cross bite of malocclusion in urban group and $18(8.5 \%)$ in rural group. $120(50.6 \%)$ participants were found crowding of malocclusion in urban group and $101(47.4 \%)$ in rural group. 59(24.9\%) participants were found spacing of malocclusion in urban group and $46(21.6 \%)$ in rural group (Figure-3).

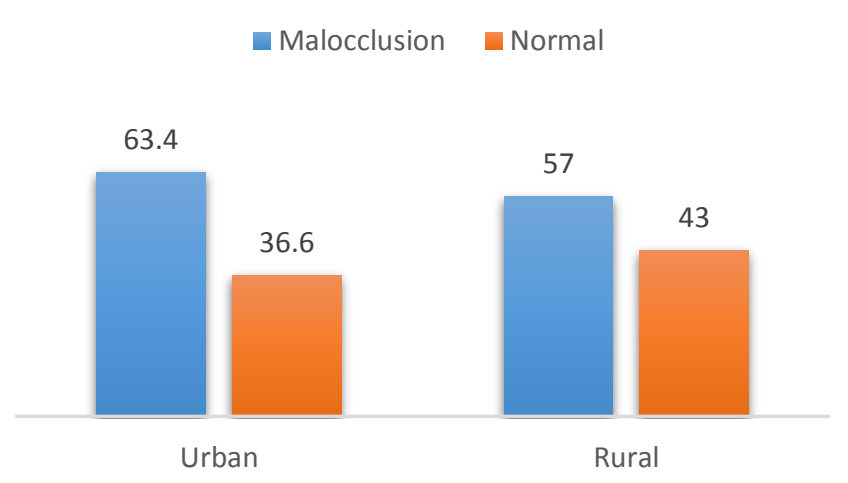

Figure 1: Prevalence of malocclusion in urban and rural school age children according to Angle's classification

Website: https://www.banglajol.info/index.php/UpDCJ 


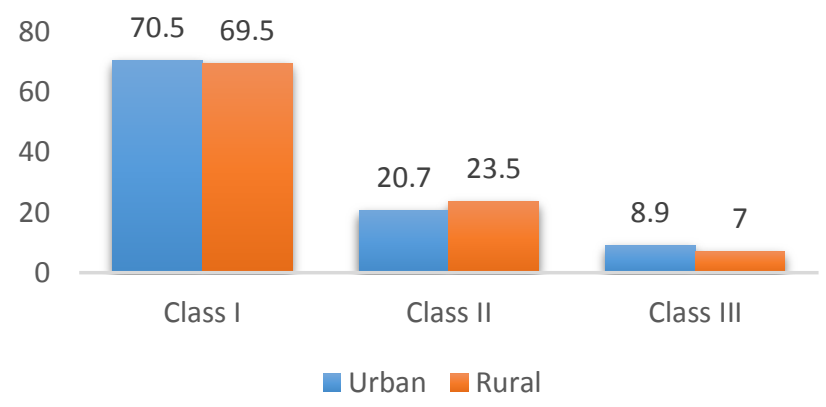

Figure 2: Frequency of malocclusion in Urban and Rural school age children according to Angle's classification

Table 1: Sex wise distribution of malocclusion of urban school age children

\begin{tabular}{|c|c|c|c|c|}
\hline \multirow[t]{2}{*}{ Occlusion } & \multicolumn{2}{|c|}{ Sex } & \multirow{2}{*}{$\begin{array}{l}\text { Total } \\
\text { n (\%) }\end{array}$} & \multirow{2}{*}{$\begin{array}{l}p \\
\text { value }\end{array}$} \\
\hline & $\begin{array}{l}\text { Boys } \\
\text { n (\%) }\end{array}$ & $\begin{array}{l}\text { Girls } \\
\text { n (\%) }\end{array}$ & & \\
\hline Malocclusion & $109(58.3)$ & $128(68.4)$ & $237(63.4)$ & \\
\hline Normal & $78(41.7)$ & $59(31.6)$ & $137(36.6)$ & $0.041^{\mathrm{s}}$ \\
\hline Total & $187(100.0)$ & $187(100.0)$ & $374(100.0)$ & \\
\hline
\end{tabular}

$\mathrm{s}=$ significant

$P$ value reached from chi square test

Table 2: Sex wise distribution of malocclusion of rural school age children

\begin{tabular}{lllll}
\hline \multirow{2}{*}{ Occlusion } & \multicolumn{2}{c}{ Sex } & $\begin{array}{l}\text { Total } \\
\mathbf{n}(\%)\end{array}$ & p value \\
\cline { 2 - 4 } & $\begin{array}{l}\text { Boys } \\
\mathbf{n}(\%)\end{array}$ & $\begin{array}{l}\text { Girls } \\
\mathbf{n}(\%)\end{array}$ & \\
\hline Malocclusion & $96(51.3)$ & $117(62.6)$ & $213(57.0)$ & $0.028^{s}$ \\
\cline { 2 - 4 } Normal & $91(48.7)$ & $70(37.4)$ & $161(43.0)$ & \\
\hline Total & $187(100.0)$ & $187(100.0)$ & $374(100.0)$ & \\
\hline $\begin{array}{l}\text { S= significant } \\
\text { P value reached from chi square test }\end{array}$ & & &
\end{tabular}

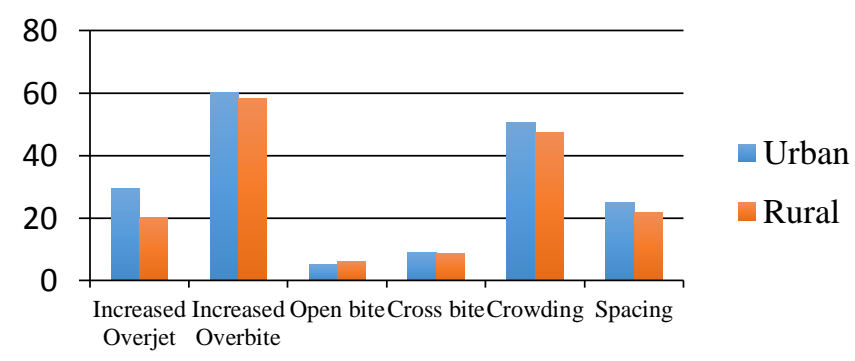

Figure 3: Malocclusion traits in urban and rural school age children according to Angle's classification

13| P a g e
DISCUSSION

In Bangladesh, most of the population does not have access to orthodontic treatment care. The orthodontic treatment by specialists is even less nearby for those who cannot afford private sector care, entry to orthodontic treatment is quite possible, essentially in public hospital or medical universities, but these cannot encounter the full ultimatum for care. Many studies on the prevalence of malocclusion in different populations have been published through world along with Bangladesh. But there are little previous information regarding comparison of prevalence of malocclusion between urban versus rural school- age children in Bangladesh.

This cross sectional descriptive survey was conducted among urban (374) and rural (374) school- age children aged 08-12 year old of Sylhet Sadar Upazila in Bangladesh. Boys and girls were equally distributed. The children were examined for Class I, Class II, Class III molar relationship, increased over jet, increased over bite, open bite, crowding, cross bite and spacing according to Angle's classification.

In current study, it was observed that (63.4\%) of participants in urban and $213(57.0 \%)$ rural area had some sorts of malocclusions. However, the difference was not statistically significant $(p>0.05)$ between two groups. The prevalence of malocclusion in urban school age children was higher than rural in this study. Similar observation was found in the study by Kaur et $\mathrm{al}^{13}$. They reported that malocclusion was widely spread among population of Karnataka state (South India), with greater prevalence in urban population than rural. Interestingly the prevalence of malocclusion in rural school children was higher than urban in Peshawar district reported by Khan et al ${ }^{10}$.

In this present study it was observed that majority (70.5\%) participants were found Angle's class I in urban group and 148(69.5\%) in rural group. Prevalence of malocclusion according to Angle's classification: In urban area, the prevalence of Angle's Class-I, II and III malocclusion was 167 (70.5\%), $49(20.7 \%)$ and $21(8.9 \%)$ respectively while in rural area, the values were 148 (69.5\%), 50 (23.5\%) and 15 (7.0\%). In India study by Kaur et al $^{13}$. also reported similar observation they showed that Angle's class I was the most prevalent malocclusion which was (89.45\% ). The result also agreement in Bangladeshi study by Rita et al $^{12}$,they reported that Angles Class I malocclusion was seen to be the most prevalent (64.2\%). However, contraindicated observation was found by Abu Alhaija et al $^{14}$ they reported Angles class II was the most commonly occurring malocclusion in north Jordanian school children.

The present study found $109(58.3 \%)$ participants had malocclusion in boys and $128(68.4 \%)$ in girls group. The difference was statistically significant $(p<0.05)$ between two groups. Prevalence of malocclusion in girls was more than boys

Website: https://www.banglajol.info/index.php/UpDCJ 
in both urban and rural area. This statement also similar to Khan et $\mathrm{al}^{14}$. They showed the prevalence of malocclusion higher in girls in comparison to boys.

This present study showed that $70(29.5 \%)$ participants were found increased overjet with malocclusion in urban group and $43(20.2 \%)$ in rural group.The difference was statistically significant $(p<0.05)$ between two groups. An Indian study by Kaur et $\mathrm{a}^{13}$. reported excessive overjet was seen in $33.71 \%$ .The difference between urban and rural population was statistically significant $(P=0.000)$ with urban population having more of an increased overjet that result is an agreement with our finding. However Khan et $\mathrm{al}^{10}$. reported that the distribution of increased overjet was more in rural (28.21\%) than urban $(18.18 \%)$ among school children of Peshawar. This statement was different from our study.

In current study it was observed that $143(60.3 \%)$ participants were found increased overbite with malocclusion in urban group and $124(58.2 \%)$ in rural group. The difference was not statistically significant $(p>0.05)$ between two groups. In an Indian study by Kaur et $\mathrm{al}^{13}$. reported deep-bite was seen in $35.97 \%$ of total sample with no statistically significant difference between urban and rural population $(P=0.083)$. The result of this study was different from Khan et $\mathrm{al}^{10}$. study who reported that the distribution of increased over bite in rural school children (24.36\%) was more than in Urban(14.69\%) of Peshawar district.

In this study it was reported that $12(5.1 \%)$ participants were found open bite in urban group and $13(6.1 \%)$ in rural. The difference was not statistically significant $(p>0.05)$ between two groups. But the result of study was different from the study of Khan et $\mathrm{al}^{10}$. The distribution of open bite in school children of Peshawar district was more in rural $10.26 \%$ than Urban $(23.78 \%)$.

In this study it was observed that 22(8.9\%) participants were found crossbite with malocclusion in urban Group and $18(8.5 \%)$ in rural group. The difference was statistically significant ( $p>0.05)$ between two groups. The result of our study was almost similar to the study by Kaur et $\mathrm{al}^{13}$. who reported that Urban population had $8.25 \%$ and rural had $8.56 \%$ anterior crossbite with no statistically significant difference $(P=0.816)$. In Peshawar district, Khan et $\mathrm{al}^{10}$. reported that rural school children had $17.95 \%$ crossbite while in urban $9.79 \%$.

In this study it was found that $120(50.6 \%)$ participants had crowding with malocclusion in urban group and $101(47.4 \%)$ in rural group. The difference was not statistically significant $(p>0.05)$ between two groups. Kaur et a ${ }^{13}$. reported frequency of crowding was $58.12 \%$. Khan et al ${ }^{10}$. reported the distribution of various traits of malocclusion in rural school children were crowding $54.41 \%$ while in urban $55.25 \%$.

In this study it was found that 59(24.9\%) participants had spacing with malocclusion in urban group and $46(21.6 \%)$ in

14| P a g e rural group. The difference was not statistically significant $(p>0.05)$ between two groups. Khan et $\mathrm{a}^{10}$. reported the distribution of various traits of malocclusion in rural school children were spacing $11.54 \%$ while in urban $12.59 \%$ of Peshawar district. Planning and implementation of future school based awareness program can be carried out and their population can be benefited by this study. So that preventive, early orthodontic treatment can be given earlier to school age children.

\section{CONCLUSION}

Prevalence of malocclusion was found more in urban schoolage children when compared with rural. Malocclusion was significantly more in girls than boys in both urban and rural area. Angle's class-I malocclusion and Increased overbite were the most commonly occurring malocclusion of school age children from a selected urban and rural community of Bangladesh.

\section{RECOMMENDATION}

School-based education specially orthodontics treatment awareness needs to be introduced in collaboration with orthodontist, school teachers, parents, and community health educators. A purpose-oriented orthodontics study has to be included in rural and urban schools from all divisions of Bangladesh. Other landmarks of occlusion can be included for further study. Directorate General of Health Services (DGHS) may include preventive, early orthodontic treatment and dental health awareness programs for school children in NCDC projects.

\section{CONFLICT OF INTEREST:}

The author declared no conflict of interest

\section{Citation:}

Faria Tabassum Tanni, Tanzila Rafique, Tanjila Akter, Khanum Huzzatun Nahar Khawla Binta Harun, \& Gazi Shamim Hasssan. A cross sectional study to assess the prevalence of malocclusion in 0812 years old school age children of the selected urban \& rural community of Bangladesh. Update Dental College Journal, 11(2). https://doi.org/10.3329/updcj.v11i2.56071

\section{REFERENCES:}

1. McLain JB, Proffitt WR. Oral health status in the United States: Prevalence of malocclusion. J Dent Educ 1985;49:386-97. https://doi.org/10.1002/j.0022-0337.1985.49.6.tb01898.x ， PMID: 3859517

2. Reddy ER, Manjula M, Sreelakshmi N, Rani ST, Aduri R, Patil BD. Prevalence of malocclusion among 6 to 10 year old Nalgonda school children. Journal of international oral health: JIOH. $2013 \mathrm{Dec} ; 5(6): 49$. PMID: 24453444,PMCID: PMC3895717

3. Thomson H. Disturbances and disorders. In: Occlusion. 2nd ed. Oxford: Wright; 1990;p.104

4. Mitchell L, Carter NE, Doubleday B. An Introduction to Orthodontics. 2nd ed. Oxford, UK: Oxford University Press; 2001. p. 5-10.

Website: https://www.banglajol.info/index.php/UpDCJ 
5. Parmesh H, Mathur VP. National oral health care program. Indian Pediatr 2002;39:1001-5. PMID: 12466568

6. Borzabadi-Farahani A. An insight into four orthodontic treatment need indices.ProgOrthod 2011;12:132-42 PMID:22074838 DOI: 10.1016/j.pio.2011.06.001

https://doi.org/10.1016/j.pio.2011.06.001

PMid:22074838

7. Kenealy P, Frude N, Shaw W. An evaluation of the psychological and social effects of malocclusion: Some implications for dental policy making. SocSci Med 1989;28:583-91. PMID:2928834 DOI:10.1016/02779536(89)90253-0 https://doi.org/10.1016/0277-9536(89)90253-0

8. Mandeep KB, Nirola A. Malocclusion pattern in orthodontic patients. Indian J Dent Sci 2012;4:20-2. DOI: 10.4103/ijofr.ijofr_16_16

9. Suma S, Shekar BRC, Manjunath BC. Assessment of malocclusion status in relation to area of residence among 15 year old school children using Dental Aesthetic Index.Int J dent clin 2011; 3(2): 14-7.

10. Khan, D.B., Ali, S., Imdadullah. 2014. An evaluation of malocclusion in rural and urban school children of district Peshawar. JKCD, 4(2), pp.1014

11. Jubayer S, Kader MA, Sharmin S, Sultana N, Al Mamun MS. Prevalence of malocclusion among the age group of $15-25$ years in Bangladeshi population. Bangladesh Journal of Orthodontics and Dentofacial Orthopedics.

2014:8-11.

https://doi.org/10.3329/bjodfo.v4i1.35738

12. Rita SN, Hasan M, Dhar PP, Abrar MH, Sadat SA. Pattern of Malocclusion in Patients Attended in Orthodontic Department of a Tertiary Level Hospital. Journal of Bangladesh College of Physicians and Surgeons. 2019 Jun $12 ; 37(3): 119-23$. https://doi.org/10.3329/jbcps.v37i3.41733

13. Kaur, H., Pavithra, U.S. and Abraham, R., 2013. Prevalence of malocclusion among adolescents in South Indian population.J IntSoc Prevent Communit Dent, 3, pp.97-102. https://doi.org/10.4103/2231-0762.122453 PMid:24778988 PMCid:PMC4000920

14. Abu Alhaija ES, Al-Nimri KS, Al-Khateeb SN. Self-perception of malocclusion among north Jordanian school children.The European Journal of Orthodontics. 2005 Jun 1;27(3):292-5. https://doi.org/10.1093/ejo/cjh094

PMid:15947230 